Hood, M., Janney, A. \& Dameron, G. (1961) Beta-hemolytic streptococcus Group B associated with problems of the perinatal period. American Journal of Obstetrics and Gynecology, 82, 809.

Jones, H. Everley \& Howells, C.H.L. (1968) Neonatal meningitis due to Streptococcus agalactiae. Postgraduate Medical Journal, 44, 549.

Keitel, H.G., Hananian, J., Ting, R., Prince, L.N. \& Randall, E. (1962) Meningitis in the newborn infant, Journal of Pediatrics, 61, 39.

Klesius, P.H., Mathews, J.H. \& KRushak, D.H. (1973) Cellular and humoral immune response to Group B streptococci. Journal of Pediatrics, 83, 926.

LANCEFIELD, R.C. (1933) A seriological differentiation of human and other groups of hemolytic streptococci. Journal of Experimental Medicine, 57, 571.

MacKnight, J.F., Ellis, P.J., Jensen, K.A. \& Franz, B. (1969) Group B streptococci in neonatal deaths. Applied Microbiology. 17, 926.

McCracken, G.H. (1973) Group B streptococci: The new challenge in neonatal infections. Journal of Pediatrics 82, 703.
Maher, E. \& IRWIN, R.C. (1966) Group B streptococcal infection in infancy: A case report and review. Pediatrics, 38, 659.

MaNnik, M., Barringer, J.R. \& Stokes, JosePh, III (1962) Infections due to Group B beta-hemolytic streptococci: report of three cases and review of the literature. New England Journal of Medicine, 266, 910.

NyHAN, W.L. \& FouseK, M.D. (1958) Septicemia of the newborn. Pediatrics, 22, 268.

QuINN, R.W. \& LowRY, P.N. (1967) Streptococcal M protein antibodies acquired at birth. Pediatrics, 39, 778.

ROGERS, K.B. (1970) Neonatal meningitis and pneumonia due to Lancefield Group B streptococci. Archives of Disease in Childhood, 45, 147.

Wilkinson, H.W. \& EAgon, R.G. (1971) Type specific antigens of Group B type Ic streptococci. Infection and Immunity, 4, 596.

Winterbauer, R.H., Fortune, R. \& Eickhoff, T.C. (1966) Unusual occurrence of neonatal meningitis due to Group $B$ beta-haemolytic streptococci. Paediatrics, 38, 661 .

Zimmerman, R.A. \& Hill, H.R. (1969) Placental transfer of Group A type-specific streptococcal antibody. Paediatrics, 43, 809 .

\title{
Excavating pulmonary metastases in carcinoma of the cervix
}

\author{
M. G. KirubaKaran \\ M.D.
}

\author{
B. M. Pulimood \\ F.R.C.P.
}

\author{
D. RAY \\ M.R.C.P.
}

\section{Christian Medical College and Hospital, Vellore-632004, South India}

\begin{abstract}
Summary
A case of excavating pulmonary metastases from carcinoma of the cervix is described. The secondary tumour had appeared nearly 4 years after apparent 'cure' of the primary lesion by radiotherapy. The diagnosis is discussed.
\end{abstract}

\section{Introduction}

Metastatic carcinoma is often not seriously considered in the differential diagnosis of multiple, thin walled cavitary lesions in the lungs. Though relatively rare, in the absence of predisposing causes, such lesions are more apt to be caused by metastatic carcinoma than by fungal diseases (Le May and Piro, 1965). Dodd and Boyle in 1961 reported sixteen cases of excavating pulmonary secondaries and Le May and Piro in 1965 collected a total of sixty-three cases from the world medical literature and added nine cases of their own. Since then a few more similar cases have been reported by different authors (Carleson, Delclos and Fletcher, 1967; Chawla and Bery, 1967; Narain, 1972). Most of these cases had their primary lesions in the head and neck regions while only a few (nine cases) had cancer of the cervix as the primary site (Narain, 1972). This report is of a case having excavating secondaries in the lungs, from cervical carcinoma treated successfully 4 years earlier.

\section{Case report}

A 37-year-old housewife was diagnosed as having squamous cell carcinoma of the cervix stage II B, confirmed by biopsy, for which she received curative radical radiotherapy. She was symptom-free until 3 months before admission to hospital 4 years later when she developed a non-productive cough. At the time of admission, physical examination revealed a healthy woman with the only positive finding of slightly reduced breath sounds in the right interscapular area. Careful examination including pelvic examination failed to reveal any evidence of active or residual disease elsewhere. The chest X-ray showed a large cystic lesion in the right upper lobe with air-fluid level and a similar, smaller lesion in the left lower lobe (Fig. 1). Repeated sputum examinations and cultures 


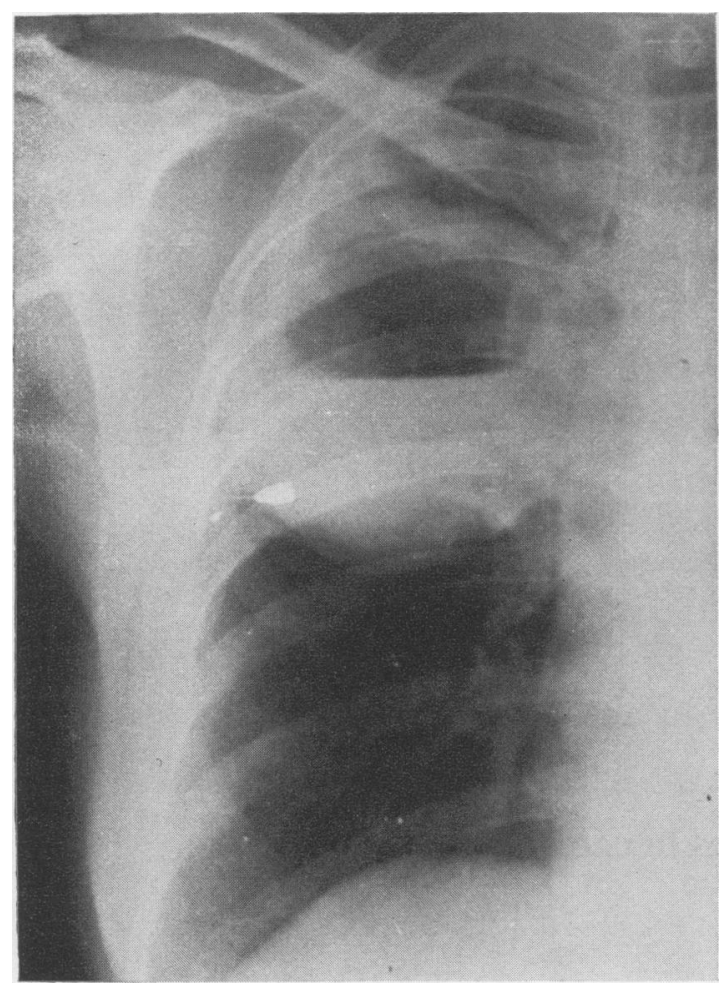

FIG. 1. Chest X-ray showing secondary tumour in the right lung with cavitation and air-fluid level.

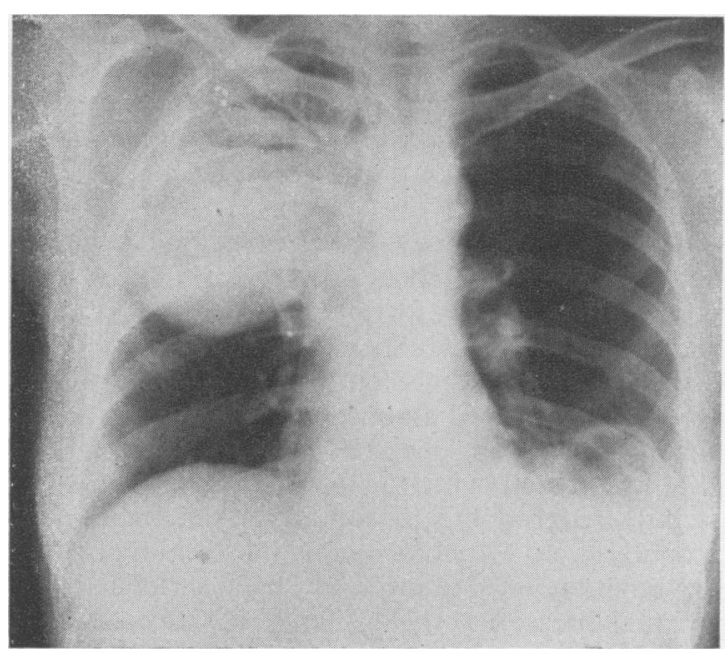

Fig. 2. X-ray taken 10 days later shows partial filling up of the cavity.

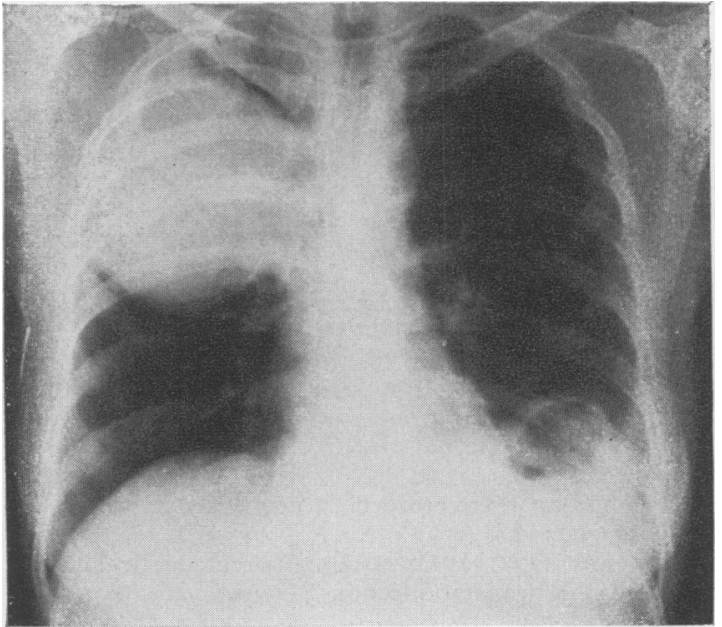

Fig. 3. Ten days after the second X-ray the cavity has filled up completely. Smaller secondary in the left base also shows thin walled cavity and air-fluid level.

were negative for pathogenic bacteria, acid-fast bacilli, fungi and malignant cells. Bronchoscopy was normal and bronchial washings failed to show malignant cells, acid-fast bacilli or fungi. Aspiration of the cavity yielded thick, mucinogenous, turbid material which was bacteriologically sterile. A drill biopsy specimen of the cavity wall showed poorly differentiated squamous cell carcinoma. The other laboratory investigations were all within normal limits. Serial chest X-rays showed a tendency of the cystic lesions to fill up spontaneously with obliteration of the airfluid levels (Figs 2 and 3).

The patient would not agree to any surgical or irradiation therapy, and was discharged.

\section{Discussion}

Secondary neoplastic lesions in the lungs which show tendency to form cystic cavities have been known for many years (Farrell, 1935). Weigh and Gillman in 1951 laid down the essential criteria for the radiological diagnosis of this condition. According to Dodd and Boyle (1961) such excavating lesions are found in $9 \%$ of primary lung tumours and only $4 \%$ of secondary lung tumours. The secondaries are commonest from squamous cell carcinomas, the majority being from the head and neck regions, and only very rarely from the pelvic region.

In primary malignant tumours of the lung a vascular necrosis is the usual cause of cavitation, but in metastatic lesions, the exact mechanism of the excavation is not clearly known. It is almost certainly not due to a simple avascular necrosis, because many of them are extremely thin walled and exhibit a 
smooth, inner surface. Most of them are squamous cell tumours which do not need as much blood supply as do other tumours, and even very small secondaries, as small as $\mathbf{8 m m}$, show definite cavitation (Dodd and Boyle, 1961)-which would be very unlikely if the cavitation were primarily due to lack of blood supply alone. Grossman, Christenson and Dillingham (1962) suggested that an altered host response to the metastatic lesions may be the cause of cavitation in these secondaries, while other workers are of the opinion that specific tissue characteristics dependent upon the cell type and the peculiar air-surrounded environment of the lung tissue may be responsible for the cavitation (Dodd and Boyle, 1961).

Pleural effusions and spontaneous pneumothorax are not common in these cases (Dodd and Boyle, 1961) and the bronchial washings are usually negative for malignant cells ( Le May and Piro, 1965). Hence the diagnosis of excavating lung secondaries is often difficult. In addition to bronchogenic carcinoma, diseases such as staphylococcal lung abscesses, fungal infections, pulmonary cysts, chronic tuberculosis and varicella pneumonia form the important differential diagnoses (Dodd and Boyle 1961). The multiplicity of these lesions in the lung fields, the tendency of these lesions to fill up and show 'airfluid' levels intermittently (Dodd and Boyle, 1961) and the sterile content of the cavities may give a clue to the correct diagnosis. Drill biopsies often confirm the diagnosis, as in the present case.

Carcinoma of the cervix usually spreads directly or through the lymphatics. Pulmonary metastasis is quite uncommon-less than $2 \%$ in a series of 2220 cases (Carleson et al., 1967)-unless there is generalized spread. Excavating pulmonary metastases from carcinoma of the cervix are rarer still and only nine cases have been reported so far (Narain, 1972). The present case resembles the case reported by Narain (1972), in that the cervix cancer had been treated successfully and the secondaries appeared after nearly 4 years of apparent 'cure'.

\section{References}

Carleson, V., Delclos, L. \& Fletcher, G.H. (1967) Distant metastasis in squamous cell carcinoma of cervix. Radiology, 88, 961.

Chawla, S. \& Bery, K. (1967) Unusual radiological manifestation of metastasis. Indian Journal of Radiology, 12, 98.

DoDD, G.D. \& BoYLE, J.J. (1961) Excavating pulmonary metastases. American Journal of Roentgenology, 85, 277.

FARRell, J.T., JR (1935) Pulmonary metastasis: pathogenic, clinical, roentgenologic study based on 78 cases at necropsy. Radiology, 24, 444.

Grossman, J.W., Christenson, R.O. \& Dillingham, C.G., $J_{R}$ (1962) Cystic liquefaction necrosis of metastatic carcinoma in the lung: a case report. Lovelace Clinical Review, 1, 143.

Le MaY, M. \& Piro, A.J. (1965) Cavitary pulmonary metastases. Annals of Internal Medicine, 62, 59.

Narain, P. (1972) Cavitating pulmonary secondaries in carcinoma cervix. Indian Journal of Radiology, 26, 144.

Weigh, R. \& Gillman, F.R. (1951) Solitary pulmonary necrosis: comparison of neoplastic and inflammatory conditions. Radiology, 56, 708. 